Eur J Clin Chem Clin Biochem

1995; 33:919-925

(c) 1995 Walter de Gruyter \& Co.

Berlin $\cdot$ New York

\title{
Medicolegal Alcohol Determination: \\ Variability of the Blood- to Breath-Alcohol Ratio and Its Effect on Reported. Breath-Alcohol Concentrations
}

\author{
By Dominick A. Labianca and G. Simpson
}

Department of Chemistry, Brooklyn College of The City University of New York, Brooklyn, New York, USA

(Received March 13/July 7, 1995)

Summary: There is substantial agreement among scientists that the variability of a person's blood- to breathalcohol ratio contributes significantly to the experimental error in results from breath-alcohol analysis. Some have argued that the need to correct for this source of error can be eliminated by reporting breath test results in units of breath-alcohol concentration rather than blood-alcohol concentration. A simple mathematical proof is presented to demonstrate that this is not the case. Moreover, the scientific and legal flaws of this argument are discussed, and recommendations are offered for dealing with the problems that have developed from adoption of this view.

\section{Introduction}

In 1990, Labianca (1) detailed the chemical basis of the operation of the Breathalyzer. That instrument - and other breath-alcohol analyzers currently used in law enforcement - employs a constant blood- to breath-alcohol ratio (hereinafter termed, "blood/breath ratio") to convert the breath-alcohol concentration of a DrivingWhile-Intoxicated (DWI) suspect into his/her corresponding blood-alcohol concentration. The problem with this type of conversion, as emphasized by Labianca (1) and others, including Simpson (2, 3), is that it fails to take into account substantial inter- and intra-individual variations in blood/breath ratios.

For many years, scientists have been acutely aware of the uncertainty associated with data generated from the uniform application of a constant blood/breath ratio to breath test subjects. In this regard, Mason and Dubowski $(4,5)$ recommended in the 1970 s that breath- to bloodalcohol concentration conversions be abandoned, and that the offense of driving-while-intoxicated be statutorily defined in terms of specified limits of breath-rather than blood-alcohol concentration in jurisdictions employing breath-alcohol analysis. That recommendation
- which was subsequently endorsed by others, including Jones (6) in 1978 - was further emphasized by Dubowski in 1983 (7), when he stressed that the proposal "simply recognizes the wide variability of the physiological blood/breath ratio." The apparent simplicity and problem-free nature of this recommendation has led to its adoption by the National Highway Traffic Safety Administration (NHTSA) of the US Department of Transportation, and has prompted a number of states in the USA during the last decade to adopt the recommendation as well and enact direct breath-alcohol statutes. Other states currently considering the recommendation may also follow suit.

The enactment of direct breath-alcohol statutes, however, has not eliminated the need to correct for the experimental error stemming from the conversion of breath- into blood-alcohol concentration via multiplication of the former by a constant blood/breath ratio. In fact, the enactment of such statutes has, in at least one case, resulted in the legislation of incorrect science.

Using an elementary mathematical analysis, this article focuses on the scientific reasons why direct breath stat- 
utes are not acceptable and also proposes the means by which the problems created by such statutes can be remedied.

\section{Scientific and Legal Overview}

The first demonstration of the incorrect science embodied in a particular breath-alcohol concentration statute, namely the California statute, was documented by Simpson (8). He showed that, implicit in the statute, is an equation that incorrectly describes the relationship between blood- and breath-alcohol concentration in a human subject. The California statute criminalizes driving with $0.08 \%$ or more by weight of alcohol in blood $(0.8$ $\mathrm{g} / \mathrm{l}$ blood), and permits $0.08 \%$ by weight to be established by either $0.08 \mathrm{~g} / 100 \mathrm{ml}$ blood (blood-alcohol concentration) - that is, $0.8 \mathrm{~g} / \mathrm{l}$ blood - or $0.08 \mathrm{~g} / 2101$ breath (breath-alcohol concentration), which is 0.00038 $\mathrm{g} / 1$ breath. If, however, $0.08 \mathrm{~g} / 100 \mathrm{ml}$ blood $(0.8 \mathrm{~g} / 1$ blood) $=0.08 \%$ by weight, and $0.08 \mathrm{~g} / 2101$ breath $(0.00038 \mathrm{~g} / \mathrm{l}$ breath $)=0.08 \%$ by weight, then it necessarily follows that $0.08 \mathrm{~g} / 100 \mathrm{ml}$ blood $(0.8 \mathrm{~g} / 1 \mathrm{blood})$ $=0.08 \mathrm{~g} / 210 \mathrm{l}$ breath $(0.00038 \mathrm{~g} / \mathrm{l}$ breath $)$, and that blood-alcohol concentration equals breath-alcohol concentration. The California legislature thus put into law the relationship, blood-alcohol concentration (BAC) equals breath-alcohol concentration (BrAC), which is incorrect. In fact, $\mathrm{BAC} \propto \mathrm{BrAC}$, so that, at a given temperature, the correct relationship describing the partitioning of alcohol between a test subject's blood and breath is given by equation 1 .

$$
\mathrm{BAC}_{\text {Act. }}=\mathrm{R} \times \mathrm{BrAC}_{\text {Meas. }}
$$

In this equation, $\mathrm{BAC}_{\mathrm{Act}}$ is the actual blood-alcohol concentration that would correspond to the result of a direct analysis of the subject's blood if he/she opted for such an analysis; $\mathrm{BrAC}_{\text {Meas. }}$ is the measured breath-alcohol concentration that would characterize the subject if he/she opted for a breath test instead; and $\mathrm{R}$ is the subject's blood/breath ratio at the time of the breath test.

In contrast to California are those jurisdictions that have enacted statutes defining driving-while-intoxicated in terms of blood-alcohol concentration and a coexisting breath-alcohol concentration, the former serving as the basis for the evaluation of driving-while-intoxicated suspects unable, or unwilling, to undergo a breath test. While these statutes do not contain the incorrect relationship, blood-alcohol concentration equals breath-alcohol concentration, they embody other scientific and legal flaws. These stem from the fact that, a specific breath-alcohol concentration limit is probative if and only if there is sufficient ethanol in the blood to produce the state of intoxication defined by the breath-alcohol concentration limit. That condition must be met, for it is possible to obtain a breath-alcohol concentration result equal to, or in excess of, a statutory limit when there is little or no ethanol in the blood. This can occur, for example, if a test subject's breath is contaminated by mouth alcohol $(9,10)$ and/or by a compound capable of producing a false ethanol reading on a breath analyzer $(11,12)$. Direct breath-alcohol concentration statutes, therefore, merely assume that, in all cases, there is sufficient ethanol in the blood to produce breath-alcohol concentration results indicative of driving-while-intoxicated. Thus, these statutes, in conjunction with the direct blood-alcohol concentration statutes that they must necessarily coexist with, "lock into place" equation 2, where $\mathrm{k}$, in contrast to $\mathrm{R}$, is the assumed blood/breath ratio for all test subjects.

$$
\mathrm{BAC}_{\text {Act. }}=\mathrm{k} \times \mathrm{BrAC}_{\text {Meas. }}
$$

\section{Scientific and Legal Flaws}

In the context of specific statutory limits in the USA, $\mathrm{BAC}_{\mathrm{Act} .}$ and $\mathrm{BrAC}_{\text {Meas. }}$ are typically defined in terms of the same weight of alcohol in two different phases for example, $0.10 \mathrm{~g} / 100 \mathrm{ml}$ blood $(1.0 \mathrm{~g} / 1 \mathrm{blood}$, liquid phase) and $0.10 \mathrm{~g} / 2101$ breath $(0.00048 \mathrm{~g} / 1$ breath, gas phase). The latter concentration is equal to $48 \mu \mathrm{g} / 100$ $\mathrm{ml}$ breath, which reflects the concentration unit used in some European jurisdictions $\left.(13,14)^{1}\right)$. Under these circumstances, $\mathrm{k}$ must equal 2100. A constant blood/ breath ratio, therefore, is applied to all drivers and is used by a legislature to set a breath-alcohol concentration limit when equation 2 , with $\mathrm{k}=2100$, is solved for $\mathrm{BrAC}_{\text {Meas. }}$, as expressed by equation 3 .

$$
\mathrm{BAC}_{\text {Act. }} \times \frac{1}{2100}=\mathrm{BrAC}_{\text {Meas. }}
$$

A statute that establishes a specific breath-alcohol concentration limit in this way does not solve the problem of blood/breath ratio variability that Dubowski $(4,5,7)$ and Jones (6) sought to eliminate. It simply ignores that variability, which is the essence of its scientific flaw. Moreover, since the statute operates under the assumption that any driving-while-intoxicated suspect who undergoes a breath test is characterized by a $2100: 1$ blood/breath ratio, it is also legally flawed; if the statute does "greatly enhance the investigation and disposition of [driving-while-intoxicated] charges", as claimed by Dubowski (7), it does so by inappropriately relieving the

\footnotetext{
1) International scientific bodies, however, recommend use of SI units: $0.8 \mathrm{~g} / 1=17.4 \mathrm{mmol} / 1$; conversion factor: $\mathrm{g} / 1 \times 21.71$ $=\mathrm{mmol} / \mathrm{l}$.
} 
prosecution of its burden to establish that the defendant had a blood/breath ratio of $2100: 1$ or more at the time of the breath test. That is, this assumption precisely fits the definition of a presumption, which is a legal inference of the existence or truth of a fact for which there is not direct evidence, but which is determined by inference from the existence of a foundational fact (15). Thus, for breath-alcohol concentration statutes, the foundational fact is the existing blood-alcohol concentration limit used for blood tests, and from this, a breath-alcohol concentration limit is inferred by assuming the existence of a constant blood/breath ratio, namely $2100: 1$, to relate the two via equation 3 . A critical point, however, is that, when used to construct statutes or to establish facts in criminal cases, a presumption must be rebuttable. Because a presumed fact may not be correct in a given case, due process guarantees of the 14th Amendment of the US Constitution require that the defendant be allowed to rebut that presumption. That certainly would be the situation if, for example, the presumption of a $2100: 1 \mathrm{blood} / \mathrm{breath}$ ratio were to be applied to a driver characterized by a $1600: 1 \mathrm{blood} / \mathrm{breath}$ ratio instead of a $2100: 1$ ratio at the time of his/her breath test. Assuming no other sources of error, this would result in an overestimate of actual blood-alcohol concentration by $31 \%$, which is equivalent to stating that actual bloodalcohol concentration would be about $24 \%$ less than the blood-alcohol concentration derived from breath-alcohol analysis.

How can this situation be remedied, given that a breath analyzer cannot adjust for the variability of each test subject's blood/breath ratio and, therefore, cannot function on the basis of equation 1 ? The answer is provided below within the context of a straightforward mathematical analysis.

\section{The Role of the Multiplication Property of Equality}

Consider that, for many years, the analytical method used by law enforcement agencies in the USA and elsewhere to determine a driving-while-intoxicated suspect's blood-alcohol concentration has involved the determination of the suspect's $\mathrm{BrAC}_{\text {Meas. }}(\mathrm{g} / 100 \mathrm{ml}$ breath or $\mathrm{g} / \mathrm{l}$ breath) and its conversion into the corresponding estimated blood-alcohol concentration $\left(\mathrm{BAC}_{\mathrm{Est}}\right)(\mathrm{g} / 100 \mathrm{ml}$ blood or $\mathrm{g} / \mathrm{l}$ blood) via equation 4 .

$$
\mathrm{BAC}_{\text {Est. }}=2100 \times \mathrm{BrAC}_{\text {Meas. }}
$$

This equation is clearly a specific application of equation 2 and, in fact, dictates that $\mathrm{BAC}_{\text {Est. }}=\mathrm{BAC}_{\mathrm{Act}}$. when the $2100: 1$ ratio is the actual blood/breath ratio of the suspect at the time of his/her breath test, and no other sources of error exist. Furthermore, it should be noted that, for blood-alcohol concentration statutes based on breath testing and, therefore, relying on equation 4, the foundational fact is $\mathrm{BrAC}_{\text {Meas. }}$ and the existence of a $2100: 1 \mathrm{blood} / \mathrm{breath}$ ratio is assumed to obtain the presumed fact, $\mathrm{BAC}_{\mathrm{Est}}$.

Obviously, when the driving-while-intoxicated suspect's ratio differs from $2100: 1$, equation 4 becomes an incorrect indicator of his/her actual blood-alcohol concentration and must be transformed into the equivalent of equation 1 to correct for the error arising from the suspect's blood/breath ratio. Given the construction of current blood-alcohol concentration statutes involving breath testing and consistent with equation 4 , a practical way to effect this transformation is to multiply both sides of equation 4 by the dimensionless correction factor, $R / 2100$, to give equation 5 .

$$
\underbrace{\frac{\mathrm{R}}{2100} \times \mathrm{BAC}_{\text {Est. }}}_{\mathrm{BAC}_{\text {Act. }}}=2100 \times \underbrace{\mathrm{BrAC}_{\text {Meas. }} \times \frac{\mathrm{R}}{2100}}_{\mathrm{BrAC}_{\text {Cor. }}}
$$

This operation is in accord with the application of the elementary mathematical axiom, the multiplication property of equality (16), to equation 4 . This procedure, which has been described elsewhere (17), necessarily dictates that both sides of equation 4 must be multiplied by the same non-zero quantity if the equality reflected by the equation is to be retained and an equivalent equation is to be produced. Equation 5, clearly the equivalent of equation 1 , relates $\mathrm{BAC}_{\text {Act. }}$ to the corrected breathalcohol concentration $\left(\mathrm{BrAC}_{\mathrm{Cor}}\right)$.

Since the variability of the blood/breath ratio generates errors in values of $\mathrm{BAC}_{\text {Est. }}$ provided by equation 4 , a point explicitly acknowledged by Dubowski $(4,5,7)$ and Jones $(6,18)$, equation 5 provides an acceptable method of dealing with those errors, which can be substantial and, therefore, detrimental to defendants in drivingwhile-intoxicated cases $(2,3,19,20)$. While it is possible to determine $\mathrm{R}$ for each individual at the time of a breath test, it is not practical. Consequently, to make corrections in $\mathrm{BAC}_{\mathrm{Est} .}$ according to equation 5, the only approach at present is to use population data for blood/ breath ratios corresponding to appropriate confidence limits. As recently stated by Rainey (21), who relied on lognormal-transformed data, mean \pm 2.58 SD $(99 \%$ confidence limits) is the appropriate confidence interval for conversions of body-fluid alcohol concentrations when a standard of "beyond a reasonable doubt" is required. The same correction can be applied to values of $B C_{\text {Est. }}$ when multiplying them by $R / 2100$ by setting $R$ equal to "mean - 2.58 SD". This "mean" would correspond to the lognormal-transformed mean blood/breath 
ratio derived from population data associated either with the absorptive or postabsorptive states of alcohol consumption $(2,3,19-20)$.

For some reason, Dubowski and Jones chose not to endorse this use of corrected blood-alcohol concentration results for breath resting. Instead they claimed that reporting breath test results in terms of breath-alcohol concentration would eliminate use of the $2100: 1$ ratio and, therefore, the necessity for correction. In other words, by claiming there is no need to correct breath-alcohol concentration results, Dubowski and Jones concluded that, $\mathrm{BrAC}_{\text {Meas. }}=\mathrm{BrAC}_{\text {Cor. }}$. The latter equation, however, can only be derived by violating the multiplication property of equality. That is, for example, when both sides of equation 5 are multiplied by the reciprocal of the $2100: 1$ ratio, in accord with the multiplication property of equality, equation 6 is obtained, demonstrating unequivocally that $\mathrm{BrAC}_{\text {Meas. }} \neq \mathrm{BrAC}_{\text {Cor., }}$ except as noted below.

$$
\text { BAC }_{\text {Act. }} \times \frac{\therefore 1}{2100}=\mathrm{BrAC}_{\text {Meas. }} \times \frac{\mathrm{R}}{2100}=\mathrm{BrAC}_{\text {Cor. }}
$$

Notice that equation 6 requires that $\mathrm{BrAC}_{\text {Meas. }}$ be multiplied by $\mathrm{R} / 2100$ to yield $\mathrm{BrAC}_{\text {Cor., }}$ just as a driving-while-intoxicated defendant is permitted to multiply $\mathrm{BAC}_{\mathrm{Est}}$. by $\mathrm{R} / 2100$ to obtain $\mathrm{BAC}_{\mathrm{Act} \text {. }}$ in order to correct breath test results reported in terms of blood-alcohol concentration. ${ }^{2}$ ) Notice too the sole condition under which equation 6 becomes identical to equation 3 and is, therefore, consistent with "locked-into-place" equa-

2 One of the reasons for adopting a recommendation that violates multiplication property of equality is the following: by expressing breath-alcohol concentration results in the USA in units of $g / 210 \mathrm{l}$ breath, manufacturers can supply identical breath-alcohol analyzers nationwide. This eliminates the need for different models in "breath-alcohol concentration and blood-alcohol concentration jurisdictions" as long as the concentration units do not have to be recorded on the evidence card, i. e., as long as only the numerical value is reported. However, the fact that the same breath-alcohol analyzers calibrated in the same way can now be used in both "breath-alcohol concentration and blood-alcohol concentration jurisdictions" is a clue that nothing is really changed by enacting direct breath-alcohol concentration statutes. Is there really any substantive difference between a legislature requiring that breath-alcohol analyzers use 2100 to convert measured breath-alcohol concentration results to blood-alcohol concentrations, and a legislature that uses 2100 to convert an existing blood-alcohol concentration limit to a breath-alcohol concentration limit? In the former case, the equation, $\mathrm{BrAC} \times 2100=\mathrm{BAC}$, is used to convert a breath test result into a corresponding blood-alcohol concentration result; in the latter case, the same equation - in the form, $\mathrm{BrAC}=\mathrm{BACl}$ 2100 - is used to set a statutory limit for breath-alcohol concentration, and measured breath-alcohol concentrations are compared to this new limit. The two approaches are, in fact, equivalent, as shown by use of the same equation, but the latter approach creates legal difficulties that appear to violate due process guarantees in the US Constitution. tion 2: only when a subject's blood/breath ratio at the time of his/her breath test is $2100: 1$. The difficulties created by Dubowski and Jones' claim, therefore, arise from an elementary error, namely inappropriate use of equation 3. While this equation correctly describes the relationship between $\mathrm{BAC}_{\mathrm{Act}}$ and $\mathrm{BrAC}_{\text {Meas. }}$ in the special case where $k=2100$, it has been, and still is being used as though it is correct for all cases in which a breath test is employed.

\section{An Illustrative Case History}

The significance of equation 6 can be further gleaned from its application to an actual case described by Simpson (8). The case involved a severely asthmatic defendant charged with driving-while intoxicated in California prior to that state's adoption of its present breath-alcohol concentration statute. The charge was based on a BAC $_{\text {Est. }}$ of $0.09 \mathrm{~g} / 100 \mathrm{ml}$ blood $(0.9 \mathrm{~g} / 1$ blood). (Recall that the statutory blood-alcohol concentration limit in California is $0.08 \mathrm{~g} /$ $100 \mathrm{ml}$ blood $[0.8 \mathrm{~g} / \mathrm{l}$ blood]). The defendant presented evidence at his trial - stemming from controlled sampling of blood- and breath-alcohol conducted at some point in time after he was charged - that showed a post-peak blood/breath ratio of $1233: 1$ and that resulted in an eventual dismissal of the case. He argued that this blood/breath ratio was substantially below $2100: 1$ at the time of his breath test, and that his $\mathrm{BAC}_{\text {Act. }}\left(\mathrm{BAC}_{\mathrm{Est} .} \times \mathrm{R} / 2100\right.$, according to equation 5) was $0.05 \mathrm{~g} / 100 \mathrm{ml}$ blood $(0.5 \mathrm{~g} / 1$ blood, obtained from, $0.9 \mathrm{~g} / \mathrm{l}$ blood $\times 1233 / 2100)$. Had this defendant been charged under California's current direct breath statute which, as noted above, criminalizes breath-alcohol concentration results at, or in excess of, $0.08 \mathrm{~g} / 2101$ breath $(0.00038 \mathrm{~g} / \mathrm{l}$ breath)

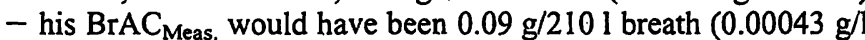
breath). He would not have been permitted to use equation 6 to convert this result into a $\mathrm{BrAC}_{\mathrm{Cor}}$ of $0.05 \mathrm{~g} / 210 \mathrm{l}$ breath $(0.00024$ $\mathrm{g} / \mathrm{l}$ breath) because, under the current statute, evidence of a defendant's blood/breath ratio has been ruled irrelevant.

The data and circumstances of this case are certainly not unique. $J$. C. Russell \& R. L. Jones (22), for example, in their study of subjects with chronic obstructive pulmonary disease - which includes conditions such as emphysema and asthma (23) - concluded that, "quantitative measurement [involving breath-alcohol analysis] must be approached with caution" when test subjects lack effective pulmonary function. In addition, Giguiere \& Simpson (20) demonstrated that a blood/breath ratio of $1233: 1$, which was exhibited by the asthmatic defendant in the above case, could also characterize an otherwise healthy subject absorbing alcohol into the circulation of the time of a breath test and faced with the same charge as that defendant. In this regard, even Mason \& Dubowski (4) said, "... when blood and breath tests are available to a subject, the breath test can be discriminatory in yielding a higher result than a blood test during absorption." So for this "healthy" subject, $\mathrm{BAC}_{\text {Act. }}$ would be $0.05 \mathrm{~g} / 100 \mathrm{ml}$ blood $(0.5 \mathrm{~g} / 1$ blood $)$ if he were to undergo a direct blood-alcohol analysis at the time his blood breath ratio was $1233: 1$, and he would not be classified drivingwhile-intoxicated in California. If, on the other hand, he were to submit to a breath test, the result, as expected, would be $0.09 \mathrm{~g} /$ $210 \mathrm{l}$ breath $(0.00043 \mathrm{~g} / \mathrm{l}$ breath), and he would be classified driving-while-intoxicated. Guilt or innocence, therefore, would depend on which test was used to evaluate the subject; while this can be true even when breath test results are reported in terms of bloodalcohol concentration, at least there is an opportunity to challenge the presumption of a $2100: 1 \mathrm{blood} / \mathrm{breath}$ ratio under those circumstances. Both of these examples reinforce the argument offered previously: enactment of direct breath statutes does not solve the problem of blood/breath ratio variability; instead, the problem is simply ignored.

$$
:
$$




\section{Constitutional Considerations and Corrections for Blood/Breath Ratio Variability}

From a legal standpoint, a legislature's use of equation 3 to set a statutory breath-alcohol concentration limit, as described above, is tantamount to instructing jurors that they are required to presume or infer that the defendant's blood/breath ratio was $2100: 1$, or greater, when he/she was tested, and that the defendant is not permitted to rebut this presumption in any way. Obviously, in a situation such as this, the asthmatic defendant in the case described above would have been unjustly convicted of driving-while-intoxicated. It is thus important that a defendant be permitted to rebut the assumption that his/ her blood/breath ratio was $2100: 1$, or greater, at the time of the breath test. Moreover, as noted previously, the use of such an irrebuttable presumption to establish an element of a criminal offense, or to criminalize certain behavior by statute, is not permitted under the due process clause of the 14th Amendment of the US Constitution; consequently, direct breath statutes, as currently formulated, appear to be unconstitutional.

Under broad police powers (15), legislatures are probably permitted to satisfy the "rational basis requirement" for enacting direct breath statutes by determining that it is dangerous for people to drive with a certain minimum breath-alcohol concentration, assuming the availability of sufficient evidence to establish that minimum. Such evidence, however, does not exist at this time. As pointed out by Simpson $(3,24)$, there is at present no established method or procedure by which alcohol-induced impairment of driving skills can be reliably related to breath-alcohol concentration; the complexity of this task is such that there is not even agreement about what test or combination of tests might be appropriate. Furthermore, breath analysis experiments that have involved impairment of some of these skills have almost always employed only postabsorptive subjects. Consequently, little is known about the relationship between breath-alcohol concentration and impairment for the period of time involving the absorption and/or equilibration-distribution of alcohol, a period of time that is often significant in forensic applications of breath-alcohol analysis. Because of this lack of appropriate experimental results involving impairment, the only means available to legislatures at present to set a statutory breathalcohol concentration limit is to base it on an existing blood-alcohol concentration limit, and that is what has been done in a number of cases. There is still a need, however, to allow for the error in breath test results due to variability of the blood/breath ratio, and this could be accomplished by means of equation 6 . This would be a scientifically and legally sound alternative to the position taken by Mason \& Dubowski (4), namely that a breath-alcohol concentration corresponding to a statutorily defined blood-alcohol concentration limit "may be directly calculated by using this [2100:1] ratio." But implementing such a "calculation" would depend on equation 3 and would, therefore, preclude the use of equation 6 to correct for the analytical error arising from the variability of the blood/breath ratio. Similarly, Jones has also acknowledged that specific blood/breath ratios have been used to set statutory breath-alcohol concentration limits both in the USA and elsewhere $(18,25)$, a procedure restricted, once again, to the use of equation 3 , or a modification of that equation when a ratio other than 2100:1 was involved. (With regard to the latter point, a blood/breath ratio of $2000: 1$ is used in Austria, and 2300:1 in Great Britain and The Netherlands [18].)

It should be noted that the matter of correcting raw data obtained from breath-alcohol analyses, in a manner conforming to the constitutional guarantees of defendants in criminal proceedings, has not been entirely ignored by Dubowski and Jones. Dubowski (26), for example, indicated a subtraction factor of $0.025 \mathrm{~g} / 100 \mathrm{ml}$ blood $(0.25$ $\mathrm{g} / \mathrm{l}$ blood), for $99.7 \%$ confidence limits at a $\mathrm{BAC}_{\text {Est. }}$ of $0.10 \mathrm{~g} / 100 \mathrm{ml}$ blood $(1.0 \mathrm{~g} / 1 \mathrm{blood})$. This adjustment represents a $25 \%$ correction factor for the variability in the blood/breath ratio, based on postabsorptive data obtained by Dubowski (27). If applied to a postabsorptive $\mathrm{BrAC}_{\text {Meas. }}$ of $0.10 \mathrm{~g} / 2101$ breath $(0.00048 \mathrm{~g} / 1$ breath), this correction would be equivalent to $0.025 \mathrm{~g} / 2101$ breath $(0.00012 \mathrm{~g} / 1$ breath). Dubowski (26) stated, however, that such a correction would be unnecessary if a direct breath-alcohol concentration statute were to be enacted.

Dubowski (o. c. (26), 18-57; 18-68) also indicated, apparently on the basis of work reported in 1981 (28), that a subtraction factor of $0.03 \mathrm{~g} / 2101$ breath $(0.00014 \mathrm{~g} / 1$ breath $)$ at a $\mathrm{BrAC}_{\text {Meas. }}$ of $0.10 \mathrm{~g} / 210 \mathrm{l}$ breath $(0.00048 \mathrm{~g} / \mathrm{l}$ breath) be used to correct for variability in Breathalyzer $900 \mathrm{~A}$ test results compared to corrresponding analyses by gas chromatography. At a $\mathrm{BAC}_{\text {Est. }}$ of $0.10 \mathrm{~g} / 100 \mathrm{ml}$ blood $(1.0 \mathrm{~g} / \mathrm{l}$ blood $)$, the subtraction factor would be $0.03 \mathrm{~g} / 100 \mathrm{ml}$ blood $(0.3$ $\mathrm{g} / 1$ blood). In this case, however, Dubowski maintained that, unless other means were adopted, it would be necessary to take this subtraction factor into account for every breath test result in order to correct for error from this source.

Jones (25), on the other hand, suggested that, for " $99.9 \%$ confidence [which] gives the defendant an acceptable margin of safety ... at a critical legal limit," a factor of $0.015 \mathrm{~g} / 2101$ breath $(0.00007 \mathrm{~g} / \mathrm{l}$ breath) might be subtracted "from the mean of a duplicate determination on separate breaths." At a statutory 
breath-alcohol concentration limit of $0.10 \mathrm{~g} / 210 \mathrm{l}$ breath $(0.00048 \mathrm{~g} / \mathrm{l}$ breath), Jones' suggested adjustment would be equivalent to a $15 \%$ correction factor. From work published earlier by Jones (29), however, a subtraction factor of $26 \%$ would apply. for $95 \%$ confidence limits, and about $40 \%$ for $99.7 \%$ confidence limits, at a mean $\mathrm{BAC}_{\text {Est. }}$ of $0.05 \mathrm{~g} / 100 \mathrm{ml}$ blood $(0.5 \mathrm{~g} / \mathrm{l}$ blood). This work involved $506 \mathrm{blood} /$ breath pairs, breath-alcohol concentration having been measured with a Breathalyzer 900 .

In the final analysis, corrections such as those described above reinforce the argument that, whenever breath-alcohol testing is used to evaluate driving-while-intoxicated suspects, the variability of the blood/breath ratio cannot be ignored. This is consistent with the view that legislatures are not permitted to employ an irrebuttable presumption - that is, effectively mandating an assumption that any driver who has ingested alcohol has a blood/breath ratio of $2100: 1$ - to construct a direct breath-alcohol statute of the type endorsed by Dubowski and Jones, and, consequently, dependent on equation 3.

\section{References}

1. Labianca DA. The chemical basis of the Breathalyzer: a critical analysis. J Chem Educ 1990; 67:259-61.

2. Simpson G. Accuracy and precision of breath-alcohol measurements for a random subject in the postabsorptive state. Clin Chem 1987; 33:261-8.

3. Simpson G. Accuracy and precision of breath-alcohol measurements for subjects in the absorptive state. Clin Chem $1987 ; 33: 753-6$

4. Mason MF, Dubowski KM. Alcohol, traffic, and chemical testing in the United States: a resume and some remaining problems. Clin Chem 1974; 20:126-40.

5. Mason MF, Dubowski KM. Breath-alcohol analysis: uses, methods, and some forensic problems - review and opinion. J Forensic Sci 1976; 21:9-41.

6. Jones AW. Variability of the blood : breath alcohol ratio in vivo. J Stud Alc 1978; 39:1931-9.

7. Dubowski KM. Driving while impaired: a proposal for statute change. Clin Chem News 1983; 9(1):4-5.

8. Simpson G. The new "direct breath" statutes: both bad law and bad science. DWI J: Law \& Sci 1991; 6(4):1-5.

9. Spector NH. Alcohol breath tests: gross errors in current methods of measuring alveolar gas concentrations. Science 1971; 172:57-9.

10. Harding PM, McMurray MC, Laessig RH, Simley DO II, Correll PJ, Tsunehiro JK. The effect of dentures and denture adhesives on mouth alcohol retention. J Forensic Sci 1992; 37:999-1007.

11. Edwards ME, Giguiere W, Lewis D, Baselt RC. Intoxilyzer interference by solvents. J Anal Toxicol 1986; 10:125.

12. Giguiere W, Lewis D, Baselt RC. More proof that solvents cause false high readings on Intoxilyzers. DWI J: Law \& Sci $1991 ; 6(4): 5-6$.

13. Gatt JA. The effect of temperature and blood : breath ratio on the interpretation of breath-alcohol results. New Law J 1984 Mar 16:249-52.

14. Denney RC. Solvent inhalation and apparent alcohol studies on the Lion Intoximeter 3000. J Forensic Sci Soc 1990; $30: 357-61$.
If such a device is employed, the resulting statute appears to violate the due process standard, even if the rational basis criterion is satisfied. Clearly, any suspect having an abnormally high breath-alcohol concentration for the amount of alcohol consumed, such as the asthmatic described earlier, would have his/her due process rights violated.

\section{Conclusion}

The flawed nature of direct breath-alcohol statutes can be rectified via a return to the statute construction used previously, whereby use of the $2100: 1$ ratio as applied to an individual is rebuttable in a court of law. That type of construction, which is still in place in many jurisdictions in the USA, would be consistent with equation 6 . In fact, statutes so constructed would be acceptable from both scientific and legal viewpoints and would be appropriate replacements for current direct breath statutes, which are acceptable from neither viewpoint.

15. Simpson G. Constitutional infirmities of per se statutes: a scientist's evaluation. In: Fitzgerald EF. Intoxication test evidence. 2nd rev. ed. Deerfield (IL): Clark Boardman Callaghan, 1995; 2 Appendix N.

16. Dressler I, Keenan EP. Integrated mathematics: course I. 2nd rev. ed. New York: Amsco, 1989:104.

17. Labianca DA. The concept of "percent error" in alcohol breathtests: a comment on Dubowski's " 0.025 " subtraction factor. In: Fitzgerald EF. Intoxication test evidence. 2nd rev. ed. Deerfield (IL): Clark Boardman Callaghan, 1995;1 Chapter 42.

18. Jones AW. Dilemma of a constant blood/breath ratio of ethanol in chemical test evidence of intoxication. In: Alcohol, drugs \& traffic safety. Proceedings of the T89 International Conference on Alcohol, Drugs and Traffic Safety; 1989 Oct 24-27; Chicago. Chicago (IL): National Safety Council, 1989:237-42.

19. Heifer U. Atemalkoholkonzentration/Blutalkoholkonzentration: Utopie eines forensisch brauchbaren Beweismittels. Blutalkohol 1986; 23:229-38.

20. Giguiere W, Simpson G. Medicolegal alcohol determination: in vivo blood/breath ratios as a function of time, I. In: McLinden VJ, Haney DJ, editors. Proceedings of the 27th Meeting of the International Association of Forensic Toxicologists; Perth. Perth (Australia): International 'Association of Forensic Toxicologists, 1992:494-506.

21. Rainey PM. Relation between serum and whole-blood ethanol concentrations. Clin Chem 1993; 39:2288-92.

22. Russell JC, Jones RL. Breath ethyl alcohol concentration and analysis in the presence of chronic obstructive pulmonary disease. Clin Biochem 1983; 16:182-7.

23. Tortora GJ, Anagnostakos NP. Principles of anatomy and physiology. 6th rev. ed. New York: Harper \& Row, 1990:708.

24. Simpson G. The effect of Daubert on the admissibility of HGN and direct breath test evidence. DWI J: Law \& Sci 1994; 9(5):5-12.

25. Jones AW. Physiological aspects of breath-alcohol measurement. Alc Drugs Driving 1990; 6(2):1-25. 
26. Erwin RE, Minzer MK, Greenberg LA, Goldstein HM, Bergh AK. Defense of drunk driving cases: criminal-civil. 3rd rev. ed. New York: Matthew Bender, 1992; 2:18-64.

27. Dubowski KM. Absorption, distribution, and elimination of alcohol: highway safety aspects. J Stud Alc 1985; 10 Suppl:98-108.

28. Dubowski KM. Breath-alcohol analysis after sorption on calcium sulfate: in-vitro and in-vivo studics. In: Goldberg L, editor. Alcohol, drugs \& traffic safety. Stockholm: Almqvist and Wiksell, 1981:637-47.
29. Jones AW. Precision, accuracy and relevance of breath alcohol measurements. In: Mattila M, editor. Modern problems of pharmacopsychiatry. Basel (Switzerland): S. Karger, 1976; 11:68-78.

Professor Dominick A. Labianca

Department of Chemistry

Brooklyn College of

The City University of New York

Brooklyn, New York 11210

USA

Dr. G. Simpson

P. O. Box 1551

Thousand Oaks,

California 91358

USA 
. 